\title{
A CULTURA DOS ASSUNTOS PÚBLICOS: O CASO DO "CUSTO BRASIL"
}

\author{
Dennison de Oliveira \\ Universidade Federal do Paraná
}

\begin{abstract}
RESUMO
O artigo discute as origens e transformações históricas daquele que pode ser considerado um tema central nos debates relativos ao desenvolvimento econômico no Brasil contemporâneo: as causas e as formas de se resolver o assim chamado Custo Brasil. Analiso aqui os diferentes usos que foram feitos dessa expressão por instituições e agentes específicos, os resultados obtidos e de que forma estes se relacionam com a conjuntura histórica e com a cultura política brasileira contemporâneas.
\end{abstract}

PALAVRAS-CHAVE: custo Brasil; cultura dos assuntos públicos; cultura política; cultura e poder; teoria dos discursos públicos; ação política empresarial; reformas constitucionais.

\section{INTRODUÇÃO}

A década de 1990 no Brasil foi marcada por intensos debates e disputas relativas aos diferentes projetos de reorganização econômica e política a serem conduzidos pelo Estado nacional. A abertura do mercado, a desregulamentação da economia e as privatizações promovidas a partir de 1990 anunciavam a transição de um modelo desenvolvimentista para algum outro, cujo conteúdo exato ainda é objeto de especulações, mas que certamente se caracteriza por ter um perfil que é nitidamente orientado para a retirada do Estado de vastos setores dedicados à produção e à regulação econômica, no intuito de tornar a sociedade brasileira mais competitiva numa era de globalização econômica (MARTINS, 1990, p. 32-33).

Por outro lado, a par dessa reformulação do modelo brasileiro de desenvolvimento, buscavase lograr uma permanente estabilidade econômica. Após sucessivos fracassos dos planos de estabilização, conseguiu-se, com o Plano Real de 1994, manter-se a inflação sob relativo controle. Tal sucesso para tornar-se permanente deveria, na retórica dos agentes responsáveis pela elaboração e implementação do plano, ser acompanhado de uma série de mudanças estruturais na economia brasileira, capazes de superar a crise fiscal vivida pelo Estado brasileiro e dar às suas políticas públicas condições de eficácia. É nesse sentido que se compreende a importância do debate re- lativo ao amplo processo de reformas constitucionais realizadas - e que ainda se encontra em andamento - no Brasil da década de 1990. O que está em jogo não é apenas a estabilidade econômica, mas toda uma reorientação do rumo e do sentido do modelo brasileiro de desenvolvimento e, no limite, uma mudança estrutural na forma pela qual se organizam e relacionam o Estado e os agentes econômicos privados (BRESSER PEREIRA, 1998, p. 163-214).

Esse processo de reformas econômicas e institucionais conseguiu envolver praticamente todos os setores organizados da sociedade civil, desejosos não só em dele participar mas também em influenciar seus rumos, fosse na ótica de lograr o atendimento de seus interesses imediatos, fosse para defender aquilo que consideravam como as soluções mais condizentes para com o desenvolvimento nacional.

Apesar da diversidade de grupos e entidades envolvidas nesses debates eles podem, grosso modo, ser divididos em duas grandes correntes: aqueles identificados com a necessidade e a urgência das reformas em curso (ainda que considerável grau de discordância exista por sob essa identificação) e os que defendem, ainda que sob diferentes objetivos e com ênfases diversas, a manutenção de pelo menos algumas das características do modelo desenvolvimentista até então prevalecente. Na cultura política da época convencionou- 
se chamar aos primeiros de representantes do pensamento neoliberal ou, como preferem alguns autores, de um "Brasil emergente". Os demais tornaram-se conhecidos como sendo a "esquerda brasileira" ou, como querem alguns, os representantes do "Brasil autárquico". Em que pese a precariedade dessa qualificação, tornou-se claro para qualquer observador que o debate sobre esse processo de transformações era polarizado entre os grupos que lhe eram predominantemente favoráveis e aqueles que, por princípio, opunhamse-lhe (ARAGÃO, 1996, p. 154; SAES, 1996, p. 141-147).

Nesse debate verificou-se o uso de um amplo conjunto de recursos políticos, econômicos e sociais mobilizados pelos grupos acima indicados no esforço de influenciar (ou barrar) o andamento das mudanças. Nesse sentido, toda uma série de temas, imagens e prognósticos foram criados e amplamente disseminados nessa conjuntura através principalmente da imprensa, num esforço para mobilizar grupos sociais e frações de classe, buscando angariar-se apoio político para influenciar o processo de encaminhamento das reformas constitucionais.

Claro que esse processo não é específico do cenário brasileiro. Via de regra, todos os grupos politicamente atuantes nas sociedades capitalistas democráticas, em particular aqueles que detêm a hegemonia política, sempre desenvolvem um esforço considerável e de caráter permanente para dificultar a emergência e a disseminação de crenças, idéias e valores que se contraponham àqueles prevalecentes e, inversamente, esforçam-se para divulgar aqueles que são mais eficazes na defesa de seus interesses.

O enfrentamento na esfera pública entre os diferentes grupos e setores em princípio favoráveis ou contrários às reformas propostas pelo governo federal levou ao surgimento de todo um conjunto de símbolos, argumentos, palavras de ordem e idéias-chave sobre aquilo que se considerava a melhor opção naquele momento para o país. Em poucas palavras, faz sentido nos referirmos ao surgimento de uma determinada cultura afeta a este assunto público.

Novamente, não se nota aí nenhuma especificidade do caso brasileiro nessa conjuntura histórica particular. Afinal de contas, numa sociedade democrática, ou pelo menos pluralista, na qual se permite o debate público a respeito dos temas de interesse coletivo, virtualmente cada questão política acaba reunindo em torno de si um conjunto de frases e argumentos característicos, que lhes são peculiares. O que queremos dizer é que cada questão pública tende a possuir uma cultura própria, plenamente identificável e cujos temas são recorrentemente a ela associados.

As evidências disponíveis permitem perceber que, em algum momento no Brasil dos anos 1990, o debate político sobre as reformas tendeu a assumir uma característica distinta: a de ter se centrado nas discussões afetas ao chamado "custo Brasil".

Tal expressão acabou por definir, circunscrever e redimensionar o debate afeto às reformas então em curso, em boa medida por que elas afetavam diretamente os termos nos quais se dava a inserção do país na ordem econômica internacional e na divisão internacional do trabalho. Tais termos eram tidos e havidos como mensuráveis, dada a suposta objetividade das comparações realizadas entre os custos de bens e serviços oferecidos no país com relação aos seus congêneres estrangeiros. A competitividade dos produtos e serviços brasileiros, tanto os exportáveis quanto os consumidos internamente, parecia ter um vínculo direto com os componentes do assim chamado "custo Brasil".

Nesse sentido, podemos imaginar o extraordinário impacto sobre o imaginário coletivo dessas comparações, tanto sobre produtores quanto consumidores comuns, através dos exemplos abaixo, típicos da retórica que tornou tão popular a expressão "custo Brasil": "Uma corrida de táxi em Nova York sai mais em conta que uma corrida de táxi em São Paulo. Embarcar um contêiner no porto do Rio de Janeiro sai pelo dobro do que embarcá-lo em Buenos Aires ou em Montevidéu. Transportar uma tonelada de soja de Mato Grosso até o porto mais próximo sai quatro vezes o custo do transporte pelo interior dos EUA. Tomar dinheiro emprestado para implantar uma fábrica no Brasil não fica por menos de três vezes o que paga um empresário para fazer a mesma coisa num país europeu. Um televisor nacional sai mais caro do que um televisor americano ou japonês" (SILVA, 1997, p. 7).

Talvez jamais se saiba com exatidão quem e quando se cunhou tal expressão. Certamente, existem evidências de que o termo foi criado pelo Serviço de Planejamento da Petrobrás na elaboração do Contrato de Gestão de 1994 para definir 
os custos das atividades produtivas do país. Contudo, ele ganha ressonância nacional e passa a fazer parte integrante do vocabulário político do país a partir de 1995, quando a CNI (Confederação Nacional da Indústria) lança um cartilha destinada precisamente a divulgar a sua interpretação sobre o que é e como deve ser entendido o custo Brasil. É interessante examinar-se tal documento, à medida em que ele nos ajuda a entender os limites a que se remete (e nos remete) a expressão "custo Brasil", ainda mais que, certamente, ele aponta os elementos típicos da retórica afeta a este assunto. Para a CNI o Custo Brasil é todo um "conjunto de ineficiências e distorções que prejudica a competitividade do seu setor produtivo. Tais ineficiências [...] dizem respeito às relações entre Estado e setor privado, e estão expressas basicamente em uma legislação inadequada e em graves deficiências no provimento de bens públicos" (CNI, 1995, p. 2).

Mais detalhadamente, nos documentos da CNI o "custo Brasil" manifesta-se em "distorções do nosso sistema tributário, que impõe uma carga tributária desigual, com sobretaxação do setor industrial, redunda em uma inaceitável tributação sobre as exportações e sobre os investimentos e implica altos custos administrativos. Está também na legislação trabalhista, dado o excesso e a rigidez de nossos encargos e na precariedade dos nossos sistemas de educação e de saúde. Está na obsolescência da infra-estrutura de transportes, nos elevados custos portuários, na rápida deterioração das telecomunicações e no estrangulamento do sistema energético. Está presente, também, no elevado custo de financiamento que caracteriza a economia brasileira há muitos anos. Está, por fim, nos custos de transação elevados associados a um nível de regulamentação da atividade econômica excessivo e oneroso" (idem, p. 2).

Enfim, a definição da CNI para o Custo Brasil é bastante ampla, englobando praticamente todos os componentes das planilhas de custos das empresas e que, no entender da entidade, são responsáveis pelo escasso potencial competitivo da indústria brasileira, tanto no mercado interno frente à concorrência dos produtos importados, quando pela queda dos índices de exportação.

A abrangência da definição do Custo Brasil na ótica da CNI talvez tenha sido a principal responsável, a par da maciça divulgação propiciada pelos meios de comunicação daquela entidade, pela ampla disseminação do conceito entre os grupos políticos e sociais organizados no
Brasil dos anos 90. Afinal de contas, compõe o Custo Brasil não apenas os itens mais diretamente relacionados com a planilha de custos, mas também elementos que dizem respeito à forma como se organiza a redistribuição de excedentes na sociedade brasileira.

De fato, ao incluir na sua definição do termo itens como o nível de qualidade e o tipo de acesso aos serviços de saúde e educação, para não mencionar a questão da infra-estrutura de transportes, energia e telecomunicações, a CNI parece ter percebido a oportunidade de mobilizar praticamente toda a sociedade brasileira no processo de discussão e implementação das reformas que seriam capazes, não só de aumentar a competitividade de seus associados, mas também, no limite, de promover uma ampla reforma social de consequiências extremamente benéficas para o avanço da democracia e para o nível de bem-estar da sociedade brasileira. Talvez por permitir essa leitura é que o termo tenha obtido tamanha repercussão entre toda uma gama de setores sociais e políticos naquela conjuntura, sendo utilizado tanto pela esquerda quanto pelos neoliberais. Numa palavra, a CNI deu um impulso decisivo no sentido de delimitar e circunscrever os termos nos quais se daria o debate sobre as reformas então em curso no Brasil, seus méritos relativos e as várias agendas que elencariam e hierarquizariam o andamento das discussões.

Os únicos itens relacionados com a planilha de custos a não merecerem atenção na definição da CNI são, justamente, aqueles relacionados com a gerência do processo produtivo e seus índices de produtividade. De fato, a CNI em seu documento parte do pressuposto de que as "empresas industriais brasileiras passaram por um vigoroso processo de ajustamento que se refletiu em crescentes ganhos de qualidade e produtividade" (idem, p. 1). Nessa ótica, as empresas já teriam feito tudo o que estava ao seu alcance para reduzir os custos de produção e lograr uma maior competitividade. Caberia então ao Estado reduzir a carga tributária, melhorar a oferta de serviços de educação e saúde, melhorar ou privatizar os serviços públicos, reduzir a taxa de juros e desregulamentar a economia. Aos trabalhadores, por sua vez, era sugerido que renunciassem aos "privilégios" propiciados pela legislação trabalhista em prol da redução dos custos.

Enfim, a expressão "custo Brasil" parece terse constituído em marco referencial das discussões 
e debates afetos ao processo de reformas econômicas e institucionais em curso naquela conjuntura. Ou seja, a própria expressão "custo Brasil" - com suas causas, diagnósticos e estratégias para reduzi-lo - passou a ser um novo item do conjunto de debates políticos dos anos 90, que tanto englobava quanto se sobrepunha a uma série de outros temas relativos às reformas então em discussão.

Dessa forma, o interesse deste texto é, através da reconstituição dos componentes da cultura deste assunto público, examinar que atores e em que circunstâncias envolveram-se no debate, que imagens eles veiculavam, que componentes do problema eram por eles mais ou menos enfatizados, e quais as conseqüências e efeitos políticos daí esperados. Pretende-se, dessa forma, contribuir para o entendimento de alguns aspectos da cultura dos assuntos públicos brasileiros dos anos $1990 \mathrm{e}$ da correlação de forças instaurada no debate político e cultural.

Este esforço de entendimento requer algumas considerações sobre as estratégias tornadas disponíveis pela Sociologia contemporânea sobre como pode ser entendida a cultura dos assuntos e questões públicas nas sociedades capitalistas contemporâneas que vivem sob regimes pluralistas. Obviamente que o exame de um tal conjunto de métodos e técnicas não pode ser feito nos estreitos limites deste trabalho. Assim, gostaria de apresentar aqui apenas uma das opções possíveis para tratar o tema e que, à luz de minha limitada experiência, tem-se mostrado coerente e consistente tanto no que respeita à fundamentação e à coerência de seus pressupostos teóricos, quanto à eficácia e à adequação dos procedimentos metodológicos que sugere. Estarei então me referindo aqui aos autores que de alguma forma têm se empenhado no desenvolvimento de uma Teoria do Discurso Público, tais como Gamson \& Modigliani (1987, 1995), Pedriana \& Stryker (1997), bem como algumas das referências teóricas de Archer (1988). Essa teoria, embora ainda longe de se encontrar completamente amadurecida (como reconhecem seus proponentes), apresenta alguns pressupostos claramente explicitados.

O primeiro deles é o de que, numa sociedade na qual é não só é rotineiro como intenso o debate público sobre os assuntos políticos, cada questão política é contestada na arena simbólica. Em havendo liberdade e oportunidade para tanto, os grupos e facções organizados poderão e certamente contestarão as idéias e propostas de seus adversários. Propostas e projetos políticos e sociais de perfis e inspirações antagônicas, e até mesmo diferentes estratégias de implementação de um mesmo projeto político que se tenha tornado amplamente consensual podem ser e são intensamente confrontadas na arena simbólica, sob uma variedade de formas veiculadas por agentes e instituições diferentes.

O segundo é que os comentários sobre os eventos e propostas políticas são baseados nas idéias, elementos e símbolos culturalmente disponíveis. Nenhum grupo ou facção envolvido em pesados e intensos confrontos simbólicos e representacionais com seus adversários pode se dar ao luxo de lançar mão de imagens e idéias completamente originais e, por isso mesmo, não passíveis de serem identificáveis ou mesmo inteligíveis por parte da sociedade mais ampla na qual ele se insere. Assim, é importante ter em conta que os agentes envolvidos nos debates e enfrentamentos políticos tanto consomem quanto reelaboram as imagens, símbolos e representações disponíveis numa dada cultura.

E, finalmente, um terceiro e último pressuposto importante é que no processo de pesquisa e reconstituição dessa luta cultural, os elementos dos quais os agentes nela envolvidos lançam mão não são, via de regra, encontrados como itens individuais, mas sim como conjuntos organizados, conhecidos como pacotes (packages) simbólicos.

O primeiro pressuposto parece despertar pouca dúvida. É amplamente reconhecido o fato de que nos debates e enfrentamentos ocorridos na esfera pública os grupos, instituições e indivíduos buscam imprimir às suas idéias e propostas um sentido positivo e de interesse universal, ao mesmo tempo em que tentam imputar às propostas e valores explicitados por seus oponentes um caráter negativo e particularista. Assim, todo processo de transformação de interesses particulares em interesses gerais, para não mencionar a "naturalização' de temas, projetos, demandas e propostas de grupos sociais, demanda um esforço de organização e mobilização política e social, mas que também tem uma dimensão cultural.

O segundo pressuposto já requer algumas considerações adicionais. Contudo, parece claro que o esforço de produção de discursos destinados a angariar apoio a determinada causa e/ou excluir propostas antagônicas ou divergentes, é feito a partir de idéias, elementos e símbolos que já foram 
tornados culturalmente disponíveis em ocasiões anteriores. Apesar de os agentes envolvidos nas disputas e debates políticos sempre serem em grande medida produtores de imagens e símbolos culturais, é importante ter em vista que tal produção é feita primordialmente a partir de elementos disponíveis num dado cenário cultural. Mais ainda, é previsível que eles lancem mão justamente dos argumentos e idéias que sejam os mais familiares e facilmente reconhecíveis pelo conjunto da sociedade a que pertencem e, portanto, passíveis de facilitar a identificação de um número substancial de indivíduos com eles.

Aqui é útil fazer referência à contribuição de Swidler (1988), que propõem pensar a cultura como uma "caixa de ferramentas" (tool-kit) de símbolos, estórias, rituais e visões de mundo, às quais as pessoas podem recorrer em diferentes configurações, para dar conta de distintos tipos de problemas. O problema a que nos referimos neste caso é dotar de sentido o que diz respeito aos assuntos públicos, buscando conferir a determinada ordem de discurso uma preponderância sobre as outras que lhe são concorrentes. Imputar um sentido ao mundo requer um esforço, e aquelas ferramentas que são desenvolvidas, destacadas e tornadas mais prontamente acessíveis têm uma alta probabilidade de serem usadas pelos agentes sociais em determinada conjuntura histórica.

E, retomando o terceiro pressuposto mencionado, cabe desenvolver aqui a categoria dos pacotes (packages) simbólicos, que parece ser a mais original contribuição à Teoria dos Discursos Públicos, tal como é proposta pelos autores em exame. De acordo com eles, "o aspecto central de um pacote simbólico é a sua armação [...] uma idéia organizadora central [...] que dá sentido para um conjunto de eventos desconexos" (GAMSON \& MODIGLIANI, 1987, p. 5).

Um pacote apresenta um número de diferentes símbolos condensados que sugerem sinteticamente a hierarquia de posições de seus elementos constitutivos e sua estrutura central organizadora, tornando possível apresentar o pacote como um todo com uma metáfora hábil, uma frase de efeito ou outro esquema simbólico qualquer. No centro do pacote está a estrutura (frame), uma idéia central organizadora ou argumento que provê sentido para uma série de eventos, tecendo uma conexão entre eles, e remetendo-se a uma cadeia de eventos que a antecede no tempo (storyline). Tal estrutura nunca é arranjada de maneira incidental ou inocente. Muito pelo contrário, uma estrutura geralmente implica uma direção política ou uma resposta implícita para aquilo que deveria ser feito em relação à questão em debate.

O fato de tal estruturação atender a algum propósito político não quer dizer que, necessariamente, ela possa ser identificada com uma e apenas uma tendência ou corrente política. As vezes, mais de uma posição política concreta é consistente com uma única estrutura. As estruturas não podem ser confundidas com posições contra ou a favor de alguma questão política, nem pode cada pacote ser identificado com uma posição política claramente definida. Em praticamente todas as questões, há pacotes que são melhor entendidos como ambivalentes, muito mais do que contra ou a favor de determinada proposta. E é justamente dessa ambivalência, dentre outras coisas, que os pacotes mais bem-sucedidos retiram sua força. No momento em que diferentes - ou até antagônicas correntes políticas lançam mão de um mesmo pacote, pode-se afirmar que ele está obtendo ascendência sobre os demais e tornando "natural" ou "universal" determinada postura política. Nos comentários públicos, os pacotes são usualmente reconhecidos através de elementos de assinatura (signature elements) que têm implicações com a estrutura central respectiva e invocam o conjunto com símbolos condensados que se tenham tornado culturalmente disponíveis.

O que a Teoria do discurso público busca fundamentalmente entender é como tais pacotes simbólicos foram estruturados, bem como contribuir para o entendimento sobre a forma pela qual um ou alguns deles ganham ascendência sobre os demais. Para os autores citados, a relativa proeminência de um discurso sobre outro(s) só pode ser explicada através de uma análise que combine o estudo das atividades relativas à sustentação financeira, ações efetivas e ressonâncias culturais de cada um desses pacotes bem como o papel desempenhado nesses processos por parte dos agentes sociais envolvidos.

Em grande parte, a mudança cultural é resultado de iniciativas de agentes e instituições que lançam mão da criação e divulgação de tais pacotes simbólicos com vistas a atingir seus fins. Tais pacotes freqüentemente têm patrocinadores (sponsors) interessados em promover suas carreiras. Aqui o patrocínio é entendido como sendo mais do que a mera defesa de determinado pacote, envolvendo também atividades como a 
construção de discursos, propaganda, redação de panfletos e artigos e todas outras oportunidades para promover um pacote preferido.

Tais patrocinadores geralmente são entidades ou organizações representativas de setores sociais, profissionais ou políticos, as quais contam com o trabalho de assessores de imprensa, jornalistas e outros profissionais habituados ao esforço de garantir ressonância e impacto a teses e idéias na grande imprensa. É claro que as atividades dos patrocinadores dos pacotes simbólicos vão exigir um esforço contínuo de sustentação financeira. E é aqui que a Teoria dos Discursos Públicos nos provê de um nexo entre cultura e poder. É previsível que os pacotes que possam contar com patrocinadores capazes de bancar os custos de sua divulgação pela mídia tenham maiores chances de se impor no cenário geral da cultura afeta a determinado assunto público. Porém, uma maior disponibilidade de recursos não explica por si só o sucesso deste ou daquele pacote. Impõe-se por parte dos patrocinadores o esforço de realizar ações que sejam realmente efetivas no sentido de divulgar e angariar apoio para seu pacote simbólico. Numa palavra, embora a maior ou menor disponibilidade de fundos financeiros seja importante, a habilidade do patrocinador em lançar mão desses recursos também joga um papel importante nessa luta simbólica.

Finalmente, o grau maior ou menor de êxito de determinado pacote tem relação direta com a ressonância cultural que ele obtém. No entendimento de tal ressonância cumpre retomar as idéias de Swindler (1988). Por um lado, em boa medida os pacotes simbólicos constituem-se a partir de elementos culturalmente disponíveis. Por outro, é altamente provável que os agentes que os estruturam e divulgam prefiram os símbolos, imagens, discursos e idéias que sejam capazes de obter maior aprovação, consenso e repercussão na sociedade como um todo. Tanto uma coisa quanto a outra implicam um processo de seleção, por parte dos agentes, dos elementos que irão ou não compor seu pacote simbólico, para não mencionar a forma pela qual se dará sua estruturação. A ressonância cultural de um dado pacote, então, além de depender de patrocinadores hábeis e capitalizados, tem nexo com o maior ou menor grau de apelo que suas componentes e a forma pela qual elas se articulam são capazes de despertar na sociedade como um todo.
Considerando então que no Brasil da segunda metade dos anos 1990 tenha emergido um amplo e vigoroso debate sobre as origens e determinações do "custo Brasil" - o qual, por sua vez, tenha dado margem ao surgimento de uma cultura afeta a esse debate - resta examinar, nos termos propostos pela Teoria dos Discursos Públicos, quais os principais pacotes simbólicos que emergiram dessa discussão, e qual a correlação de forças que se estabeleceu entre eles.

Uma primeira constatação que deve ser feita diz respeito ao caráter composto desses pacotes. De fato, até onde pudemos perceber, os agentes e entidades dedicados a debater o Custo Brasil quase sempre se mostravam inclinados a elaborar ordens discursivas que, embora estruturados em torno de uma idéia-força central, geralmente contavam com elementos ou manifestações passíveis de serem identificados com outras idéias e propostas então em circulação. Não obstante, rigorosamente todos eles enfatizavam, no conjunto dos elementos que arrolavam, um determinado aspecto que consideravam realmente central no exame e enfrentamento da questão. É exatamente isso que nos permite reconhecer, através da forma como esses elementos isolados são estruturados, bem como pela identificação da dimensão que está sendo enfatizada, pelo menos cinco diferentes pacotes simbólicos.

\section{II. "OS ELEVADOS CUSTOS TRABALHIS- TAS"}

Uma das idéias mais recorrentes - senão $a$ mais recorrente - no debate sobre as origens e causas do "custo Brasil" é a de que os custos que incidem sobre a folha de pagamento oneram excessivamente o setor produtivo. Nessa ótica, os custos indiretos dos salários, os chamados "encargos sociais", deveriam ser reduzidos, a bem da redução geral dos custos de produção e do aumento geral da produtividade e competitividade brasileiras. Trata-se, pois, de um claro exemplo da forma pela qual um pacote simbólico - no caso, o dos "elevados custos trabalhistas" - organiza e estrutura uma determinada ordem discursiva, na medida em que ele: 1) remete-se a uma história anterior que o legitima e promove ou, se se preferir, a uma determinada versão possível da história; 2) aponta para pelo menos uma causa central do problema suscitado pelo debate sobre o Custo Brasil ; e, por extensão, já indica qual solução pode ser dada ao problema. Vejamos de que forma os agentes e 
instituições responsáveis pela promoção e divulgação desse pacote simbólico o estruturam.

Um desses agentes certamente é o Ministro da Fazenda Pedro Malan, que repetidas vezes pronunciou-se sobre o tema, menos para responder sobre as responsabilidades do Estado na composição do custo Brasil, que para sugerir que se modificassem leis que eram de interesse de outros setores sociais, notadamente da classe trabalhadora: "Nós fomos ao longo de anos colocando penduricalhos, na forma de contribuições na folha de pagamentos, fazendo com que essa diferença hoje seja superior a $100 \%$. A redução desse custo permite não só a redução do Custo Brasil mas permite o aumento do emprego e pode resultar também em aumento do salário real" (MALAN DEFENDE, 1994, p. 1-5).

Em apoio a essa postura escreveu um articulista da Revista Exame, criticando inclusive a demora do governo em agir: "[o Custo Brasil é] tudo aquilo que encarece a vida das empresas. Antes de assumir o Ministério da Fazenda, Pedro Malan o anunciou como uma de suas metas. $\mathrm{O}$ objetivo era estimular a produção e combater o desemprego. Depois da posse, Malan ganhou o apoio do colega Paulo Paiva (Trabalho). Os dois passaram a estudar formas de reduzir principalmente os encargos trabalhistas. Calculava-se que os custos trabalhistas poderiam cair até $12 \%$ " (MÃOS SEM OBRAS, 1995, p. 12).

Talvez um dos analistas do mercado mais citados na grande imprensa em se tratando da análise comparativa dos componentes do "custo Brasil" seja o Prof. José Pastore, da Faculdade de Economia e Administração da USP. Seus escritos privilegiavam a crítica aos encargos trabalhistas e a carga tributária suportada pelas empresas, recebendo sempre grande divulgação na imprensa. Por exemplo, em outubro de 1997 ele divulgava um estudo comparativo entre duas unidades fabris de uma mesma empresa, uma sediada nos EUA e outra no Brasil, permitindo daí ao leitor avaliar a participação relativa dos encargos trabalhistas e da carga tributária na composição das suas respectivas planilhas de custo.

"A fábrica de Ilhéus recolhe PIS, COFINS, IPI, IOF, CPMF, INSS, Incra, Sebrae, Sesi, Senai, FGTS, ICMS, IPTU, IPVA, IR, Contribuição sobre o Lucro, salário-educação, seguro-acidente, Imposto de Importação, guia de importação, contribuição sindical, entre outros tributos e obrigações fiscais e parafiscais. A fábrica de New Jersey paga somente a Previdência Social, seguromédico, seguro-desemprego, IPTU, e, uma vez por ano, IR. Com estrutura tributária menor, as despesas administrativas correspondem a somente $25 \%$ daquelas incorridas em Ilhéus [...]. O custo dos empréstimos também é substancialmente mais baixo, de 7,5\% ao ano, em dólar, comparativamente a $21 \%$, no Brasil. O custo da folha de salários é mais elevado, em New Jersey, mas nem nisso o Brasil está em vantagem, pois a diferença é compensada pela produtividade. $\mathrm{O}$ empregado americano ganha US\$ $1.800,00$ mensais e, com os encargos, custa US\$ 2182,50 para a empresa. Em Ilhéus, esses valores são, respectivamente, $\mathrm{R}$ \$ 650,00 e R\$ 1 373,45 (US\$ 1 280,00) [...]. Por isso, o empregado, nos EUA, custa menos para a empresa, enquanto leva muito mais dinheiro para casa: US\$ 1989,00 , em New Jersey, e US\$ 927,00, em Ilhéus (computando-se, além do salário, o décimo terceiro, adicional de férias, FGTS etc.)" (CUSTO BRASIL NA PRÁTICA, 1997, p. 13).

O encantamento com as vantagens comparativas de nossos concorrentes não tinha, entretanto, apelo universal. Uma das raras vozes que se levantaram para relativizar os supostos méritos das economias baseadas na exploração intensiva da mão-de-obra foi o ex-Ministro Mário Henrique Simonsen. "O ex-ministro da Fazenda e do Planejamento Mário Henrique Simonsen não aprova comparações automáticas entre o milagre chinês de competitividade e o alto custo Brasil, que vem tirando capacidade do País para disputar mercados. O baixo custo China está intimamente ligado ao que ele qualificou de salários miseráveis - algo que, seguramente, não se deve querer imitar. Além disso, adverte, se o custo de um país dependesse dos salários, o Japão e os Estados Unidos nada conseguiriam vender fora de suas fronteiras, pois seus trabalhadores ganham muito bem" (CUSTO BRASIL DESAFIA, 1996, p. 10).

À medida em que este pacote simbólico ia se consolidando como um componente a mais da cultura política brasileira, mais e mais setores sociais e correntes do espectro político brasileiro iam a ele se referindo ou dele lançando mão para divulgar e defender seus pontos de vista. Ao cabo de alguns anos, praticamente todos os segmentos empresariais e boa parte do poder público federal já havia incorporado, pelo menos em algum momento, o uso da expressão "os elevados custos 
trabalhistas" à sua retórica oficial.

As esquerdas e as entidades representativas da classe operária foram diretamente afetadas pela emergência do pacote dos "elevados custos trabalhistas" no cenário político, e de maneira negativa. De fato, ao centrar a armação desse pacote simbólico nos encargos sociais, tidos como um dos fatores de encarecimento dos custos de produção, os representantes empresariais acabaram por atrair ao debate sobre o Custo Brasil -e colocar numa posição desfavorável - as entidades sindicais.

Talvez a posição mais contundente nesse debate tenha sido a do já citado Prof. José Pastore. Ele ganhou notoriedade nacional ao apresentar um estudo em que apontava que os encargos sociais correspondiam a uma soma superior ao salário efetivamente pago aos empregados na indústria. Para ser mais exato, ele entendia que estes somavam $102 \%$ do salário recebido.

Logicamente, essa metodologia foi colocada em dúvida não só pelos sindicatos e outras entidades ligadas à classe trabalhadora, como também por outros representantes do espectro político brasileiro. Por exemplo, em 1996 o exMinistro da Fazenda Ciro Gomes criticava a iniciativa do Sindicato dos Metalúrgicos de São Paulo em propor ou aceitar a celebração de contratos temporários de trabalho revogando os encargos sociais estabelecidos pela legislação, incluindo os de natureza constitucional. Criticando o "dogmatismo neoliberal" que em tempos de globalização da economia e de competitividade extremada em escala planetária - que supostamente "recomendariam uma minoração de todos os custos possíveis da produção" - ele revela que, na verdade, os salários e seus respectivos encargos, no Brasil, representam parcela já muito reduzida dos custos de produção. "A atual participação dos salários no valor agregado da indústria brasileira é já uma das mais baixas do mundo, muito abaixo, inclusive do mesmo índice praticado por economias muito mais inexpressivas que a nossa. Os salários são, no Brasil, apenas 23\% do valor agregado na indústria. Segundo a Organização das Nações Unidas para o Desenvolvimento Industrial, essa estatística é de $37 \%$ no economicamente inexpressivo Panamá, 38\% na Índia, 51\% na África do Sul, ou de $69 \%$ na Itália e $71 \%$ na Noruega. Não há a menor racionalidade econômica em se reduzir ainda mais essa já ridícula participação dos salários na renda nacional. Isso seria comprimir ainda mais o já desproporcionalmente deprimido mercado interno brasileiro e agravar ainda mais uma das causas dos poucos empregos que temos em nosso País" (A POLÊMICA DOS ENCARGOS SOCIAIS, 1996, p. 7).

A questão do peso dos encargos sociais na folha de pagamentos e, por extensão, no Custo Brasil criou de fato uma enorme polêmica. Por um lado, verificaram-se consideráveis discrepâncias com relação à metodologia empregada para se medir o peso dos encargos. Dependendo da inclusão ou não das várias formas de remuneração direta que não se constituem em salário, como férias, descanso remunerado, $13^{\circ}$ etc., tal percentual variava loucamente dos citados $102 \%$ do prof. Pastore, aos 25,1\% do DIEESE (DIEESE, 1997).

Independentemente dos méritos respectivos de cada metodologia, parece ter-se disseminado amplamente entre expressivos setores políticos e sociais a idéia de que, de fato, no Brasil prevalecia uma estrutura sindical e trabalhista excessivamente rígida e ultrapassada, a par de altos encargos sociais que aumentavam desnecessariamente o custo da folha de pagamentos e encareciam o Custo Brasil. Ou seja, o pacote do peso dos encargos sociais na origem, como causa do Custo Brasil, permanece amplamente disseminado em expressivos setores políticos e sociais brasileiros, independentemente dos méritos relativos de cada uma das metodologias empregadas para sua mensuração.

De fato, este pacote parece ser hoje quase um senso comum. Tal fato colocou o movimento sindical do país numa postura essencialmente defensiva, em se tratando de discutir o Custo Brasil. Por exemplo, uma das centrais sindicais que mais rapidamente incorporou à sua agenda política a participação no debate sobre o "custo Brasil" foi a Central Geral dos Trabalhadores (CGT). Após receber a adesão de dissidentes da Força Sindical, reunidos na Frente Social-Democrata de Sindicatos, a CGT passou a divulgar um programa de combate ao desemprego pautado precisamente na redução do "custo Brasil", "mas, entendido aí que não são os encargos sociais e sim a falta de infraestrutura do País, que encarece os produtos aqui fabricados" (NOVA CENTRAL, 1996, p. 3).

Por seu lado, o Presidente da Central Única dos Trabalhadores (CUT), Vicente Paulo da Silva, 
reagiu de maneira ambígua quando convidado a se pronunciar sobre a questão: "essa questão de reduzir encargos é mais um mecanismo que, embora eu admita a idéia da competitividade, reduzir custos é uma coisa importante, mas reduzir custos no lugar certo, sem precarizar as condições de quem produz. E a nossa Central jamais fará nenhum tipo de acordo que signifique prejuízo aos trabalhadores" (SILVA, 1997, p. 187).

As tentativas de se negar ou minimizar o impacto do pacote simbólico dos "custos trabalhistas" até agora não tem dado resultado. Talvez por isso as forças políticas e sociais identificadas com a esquerda brasileira tenham relutado em lançar mão desse termo com a mesma freqüência e intensidade que seus opositores no debate político.

A rápida e ampla penetração deste pacote simbólico, tanto como diagnóstico das causas como apontando solução para o Custo Brasil aparentemente está relacionado com a habilidade e disponibilidade de recursos por parte de seus patrocinadores. Dentre estes cabe citar o próprio Palácio do Planalto e importantes entidades patronais. Por outro lado, cabe notar a ampla ressonância obtida por ele, na medida em que pesquisadores e acadêmicos, tais como o sempre muito citado Prof. José Pastore, emprestaram a esse pacote o peso de seu prestígio e autoridade, ajudando a divulgálo. Finalmente, cabe citar a escassa repercussão dos seus críticos nos órgãos de imprensa. Tal fato pode ser entendido tanto como resultado da pouca ressonância cultural de tais críticas, quanto de uma insuficiente disponibilidade de recursos para a divulgação destas. Isso se constata tanto pelo fato de que nenhuma entidade governamental ou representativa do empresariado referendou críticas ao pacote dos "elevados custos trabalhistas", quanto porque mesmo as entidades representativas dos trabalhadores que divulgaram tais críticas só as viram repercutidas nos discursos de elementos isolados, geralmente de oposição ao governo FHC (como é o caso de Ciro Gomes) ou de fora do governo (como o ex-Ministro Simonsen). A estes coube a responsabilidade de elaborar um "contrapacote", tal como entendido pela Teoria dos Discursos Públicos. Aqui é útil pensar dialeticamente nos temas em confronto: pode-se mesmo afirmar que não existe tema sem um contra-tema. Assim, ao pacote dos "elevados encargos trabalhistas" acabou correspondendo a idéia dos "salários miseráveis". Percebe-se então que o pacote dos "elevados encargos trabalhistas" é convencional e normativo, e que o contra-pacote dos "salários miseráveis" é rival e contencioso.

Mesmo supondo-se que a toda ação possa corresponder uma reação, não devemos alimentar ilusões de que os contra-pacotes, para serem efetivos, não tenham de atender aos mesmos prérequisitos já mencionados para os pacotes. Se levarmos em conta, então, a necessidade de patrocinadores e de uma ação eficaz por parte deles, já teremos reunido os elementos que nos permitem entender porque a idéia dos "salários miseráveis" sequer chegou a se constituir em um pacote simbólico: simplesmente porque não existiam patrocinadores para ele.

\section{A "ALTA CARGA TRIBUTÁRIA"}

Outro pacote de extraordinário apelo e ressonância no debate afeto às causas, diagnósticos e soluções para o Custo Brasil foi o da "alta carga tributária". Mais uma vez, como é típico da estruturação de um pacote simbólico, temos uma certa versão da histórica de como se chegou ao Custo Brasil, qual o principal problema relacionado a ele e a proposta de uma determinada forma de resolvê-lo. Aqui o aspecto central é a elevada carga tributária paga pelos produtores brasileiros, a qual onerava tanto a produção interna quanto aquela dedicada à exportação. Comparativamente aos países estrangeiros, a nossa carga tributária seria muito elevada, sem que a ela correspondesse uma contrapartida na forma de bens e serviços prestados pelo Estado. Assim, tal ônus imposto ao nosso setor produtivo seria uma das principais, senão $a$ principal, das causas do Custo Brasil. Previsivelmente, os patrocinadores deste pacote contavam com imensas vantagens e facilidades para a sua divulgação, pela ressonância que obtinham na mídia para a divulgação de suas teses, em especial a cada novo aumento de impostos ou criação de novos tributos.

Foi assim que o governo federal viu-se sob alvo de pesadas críticas, que se remetiam ao pacote da "alta carga tributária", por ocasião da criação da CPMF (Contribuição Provisória sobre Movimentações Financeiras, conhecido como o "imposto do cheque"), imediatamente identificada como um fator a mais a encarecer o Custo Brasil. Tiveram imensa repercussão os pronunciamentos de agentes e instituições indicando a perda de competitividade que adviria da cobrança do novo imposto. Por exemplo, Álvaro Augusto Vidigal, ex-Presi- 
dente da Bovespa (Bolsa de Valores do Estado de São Paulo), dizia que "o novo imposto, sozinho, significa encarecer sete vezes o custo de operação na bolsa, o que acaba inviabilizando os investimentos externos" (NOVO CUSTO BRASIL, 1996).

Como já foi dito, é perfeitamente possível, segundo a argumentação da Teoria do Discurso Público, que mais de uma posição política seja coerente com a defesa de determinado pacote simbólico. Isso fica evidente no episódio no qual o próprio governo federal acabou usando dos argumentos inerentes ao pacote da "elevada carga tributária" para justificar a lei que desonera as exportações de produtos básicos e semi-elaborados do ICMS (Imposto sobre a Circulação de Mercadorias e Serviços), conhecida como "Lei Kandir". Como vimos, a "sobretaxação" das exportações figurava na definição original da CNI sobre os componentes do Custo Brasil. Cumpre lembrar que o Brasil experimenta, desde o início do Plano Real (1994), o acúmulo de elevados e sucessivos déficits em sua balança comercial. Tal lei foi acolhida com manifestações favoráveis na imprensa que avaliava que "é preciso acelerar a redução do Custo Brasil. A desoneração do ICMS, que entra em vigor imediatamente, poderá propiciar um grande estímulo à economia [...] o melhor, é que o governo passou a combater o desequilíbrio com medidas corretas, destinadas a reduzir o Custo Brasil, fugindo ao dilema de desvalorizar o real ou perder mercado" (CUSTO BRASIL MENOR, 1996, p. 6).

Além da pressão pela redução da carga tributária, inerente a e imediatamente identificável com a estrutura do pacote da "elevada carga tributária", também os grupos em prol da privatização dos portos e/ou da desregulamentação da legislação de trabalho portuário lançaram mão da retórica inerente a esse pacote simbólico. Por exemplo, em 1996 o Presidente da Federação das Indústrias do Estado de S. Paulo, Carlos Eduardo Moreira Ferreira, o Presidente da Confederação Nacional da Indústria, Fernando Bezerra, além do coordenador do Comitê Empresarial de Competitividade, Jorge Gerdau Johanpeter, reuniram-se com os Ministros da Casa Civil, Clóvis Carvalho, e do Planejamento, Antônio Kandir, para pedir agilidade na redução dos custos portuários e pressa na votação de uma reforma tributária, justamente em nome da redução do Custo Brasil (FERREIRA PEDE PRESSA, 1997, p. 12).
Além dos exportadores, também o setor empresarial dedicado à exploração do turismo fez uso do pacote em exame para fazer valer suas reivindicações. Por exemplo, no $8^{\circ}$ Congresso Nacional da Associação Brasileira dos Restaurantes e das Empresas de Entretenimento (ABRASEL), representantes dos diversos segmentos do turismo lançaram uma campanha nacional pela redução do Custo Brasil. Segundo o Presidente da ABRASEL, Paulo César Gallindo, os empresários já teriam feito a sua parte e era hora de o governo realizar amplas reformas para incentivar o setor. $O$ que se pleiteava enfaticamente era a criação de mecanismos simplificados de cobrança de tributos, adequação das alíquotas de impostos, revisão da legislação trabalhista no que respeitava à incidência de tributos sobre a folha de pagamentos etc. De quebra, as recomendações de sempre, no que se refere à criação de novas linhas de financiamento para pequenas empresas (BONITO, MAS MALTRATADO, 1998, p. 7).

Também o setor de transportes aéreos lançou mão das imagens que remetem ao pacote da "elevada carga tributária" para fazer valer suas reivindicações e responder aos críticos dos salgados preços cobrados pelas passagens aéreas. $\mathrm{O}$ Sindicato Nacional das Empresas Aeroviárias (SNEA) enfatizava que, muito em função dos impostos inclusos, o litro do querosene de aviação custava US\$ 0,30 no Brasil e US\$ R \$ 0,15 nos Estados Unidos. As taxas dos aeroportos e tarifas de proteção, segundo o SNEA, são, no Brasil, "em média mais altas do que as suportadas pelas empresas aéreas norte-americanas"(EMPRESAS CULPAM, 1996, p. 31).

Não só empresários da indústria de transformação, exportadores e do setor de serviços se remeteram aos pressupostos e diagnósticos da "elevada carga tributária" em suas falas. Também representantes do setor agrícola lançaram mão dele. Por exemplo, obteve ampla repercussão entre as classes produtoras uma avaliação feita pelo Diretor de Economia Agrícola do Ministério da Agricultura e do Abastecimento, Benedito Rosa, em 1997. Segundo ele, o custo da produção de trigo no Brasil é quase o dobro do da Argentina e dos Estados Unidos, devido, entre outras coisas, "à carga tributária e à ineficiente infraestrutura de transporte e portuária" (CUSTO BRASIL TAMBÉM ENCARECE, 1997).

\section{A "INFRAESTRUTURA DEFICIENTE"}


Como vimos, na estruturação interna do pacote relacionado à "elevada carga tributária" encontramos recorrentemente não só a crítica ao volume de impostos cobrados do setor produtivo, mas também a insuficiente contrapartida a esses mesmos impostos sob a forma de uma adequada oferta de bens e serviços públicos, notadamente na área da infra-estrutura produtiva. Dessa forma, é possível encontrar estreitamente associado ao pacote da "elevada carga tributária" um outro pacote simbólico ou, como admite a Teoria dos Discursos Públicos, um subpacote. Referimo-nos, claro, ao tema da "infraestrutura deficiente".

Aqui, o principal atingido por esse uso do pacote era o governo federal, recorrentemente acusado de ser o responsável pelo sucateamento da infra estrutura de transportes, comunicação e energia. Uma das formas que o governo federal encontrou para recuperar a infra-estrutura de transportes em franco processo de deterioração - entendida segundo o subpacote da "infraestrutura deficiente" como uma das dimensões negativas associadas à "elevada carga tributária" - foi o investimento em obras de restauro e, mais comumente, a privatização. Por exemplo, em junho de 1997, o Presidente da República prometia que em 120 dias não haveria mais buracos nas estradas federais brasileiras e acenava com aquele que seria o cenário futuro em que a questão estaria definitivamente resolvida: "Mas não adianta querer tapar o sol com a peneira. O governo federal é incapaz de cuidar de todas as rodovias que estão sob sua responsabilidade. Está provado que a iniciativa privada tem condições de cuidar de parte das rodovias. Isto está acontecendo nas rodovias que ligam o Rio de Janeiro a São Paulo, Rio de Janeiro a Teresópolis, Rio a Juiz de Fora, Osório a Porto Alegre lá no Rio Grande do Sul, e ainda na ponte Rio-Niterói. E você que transita por esses trechos é testemunha de que o pedágio que você paga está garantindo estradas melhores. Vamos continuar a privatização e vamos dar continuidade ao programa de transferência de trechos rodoviários para os Estados" (ESTRADAS, 1997, p. 2).

Além de lideranças empresariais, as entidades representativas do setor também se manifestaram sobre as causas do Custo Brasil lançando mão do pacote da "infraestrutura deficiente". Delas, uma das mais atuantes foi a Associação Nacional das Empresas de Obras Rodoviárias, que estimava que o mau estado da rede rodoviária federal causava um prejuízo anual de $\mathrm{R} \$ 2,5$ bilhões ao país, contribuindo assim para ampliar o Custo Brasil. Também a Federação das Indústrias do Rio de Janeiro (FIRJAN) argumentava que o país pagava o sobrecusto de US\$ 3,5 bilhões por ano apenas pela retenção dos caminhões por tempo desnecessariamente longo nos mais de cem postos de físcalização espalhados pelo país. Fazia eco a essas críticas a Confederação Nacional dos Transportes (CNT), que reunia então 203 empresas transportadoras.

Tais apelos tiveram substancial repercussão, tanto entre entidades nacionais quando organismos de fomento internacionais. Igualmente preocupadas com o impacto dos custos adicionais derivados da deterioração da infra-estrutura de transportes estavam organizações como o Banco Mundial, que estimou em US\$ 3 bilhões anuais o dinheiro perdido no Brasil pela má utilização das ferrovias e pela preferência pelo transporte de carga nas estradas.

Os defensores da privatização, por sua vez, aderiram entusiasticamente e fizeram largo uso do pacote da "infraestrutura deficiente". Basicamente, defendiam que a transferência dos serviços públicos para a iniciativa privada teria um impacto substancial na redução do Custo Brasil, como demonstra o articulista de uma prestigiosa revista periódica dedicada ao temas econômicos e empresariais. Nisso faziam coro com o Palácio do Planalto: "31 portos, inclusive os do Rio de Janeiro e de Santos, já foram incluídos no programa de privatização. Esta medida, em conjunto com a transferência dos trilhos da Rede Ferroviária para operadores privados, já feita em 1996, e a concessão da Fepasa, prevista para 1997, é incluída entre as mais importantes para a redução do chamado Custo Brasil"' (QUANDO O TELEFONE, 1996, p. 22-25).

Uma das partes do conjunto de símbolos, imagens e argumentos estruturados por este pacote simbólico, em grande medida responsável pela sua ampla ressonância, era a comparação freqüente do desempenho da infra-estrutura portuária nacional com os seus congêneres estrangeiros. Em um estudo preparado pelo Conselho de Infra-Estrutura da Confederação Nacional da Indústria (CNI) divulgava-se que: "O preço médio para a movimentação de contêineres no mercado internacional fica entre US\$ 160 e US\$ 240. No Brasil, esse valor varia de US\$300, no Porto do Recife, a US\$ 
550, no Rio. A mesma disparidade acontece no tempo gasto nessas operações. Enquanto no Chile, na Alemanha e nos Estados Unidos esse número é de 22,24 e 30 contêineres por hora, no Brasil o melhor desempenho fica entre 13 e 14 contêineres por hora, no Porto de Santos" (PARA CNI, 1997, p. 5).

Essa retórica tinha um alvo bem definido. Com a divulgação desses dados a CNI visava a dar apoio às suas críticas contra o monopólio dos sindicatos de trabalhadores avulsos na contratação de mãode-obra e em favor da privatização dos portos públicos (idem). Também receberam ampla divulgação os estudos do BNDES (Banco Nacional de Desenvolvimento Econômico e Social) sobre os custos da infra-estrutura portuária, numa perspectiva comparada (PORTO BRASILEIRO, 1997, p. 8).

Desta forma, o que se nota é que o pacote simbólico da "infraestrutura deficiente" pôde contar com um expressivo número de patrocinadores, que, à medida em que se constituíam das mais importantes entidades representativas do empresariado, bem como por instituições de fomento nacionais e estrangeiras, puderam lançar mão de amplos recursos na divulgação do pacote. Conseguiram, dessa forma, disseminar entre amplos setores da sociedade nacional brasileira aquela que consideravam a melhor "saída" para os impasses apontados: a privatização e/ou desregulamentação pura e simples dos serviços públicos. Apesar de ter estado em vários momentos intrinsecamente relacionada com a questão da carga tributária, poucas foram as vozes que se levantaram para reivindicar que o setor público aplicasse melhor os tributos arrecadados na melhoria da infra estrutura econômica, e, mesmo assim, seus reclamos foram sustentados por pouco tempo.

A principal constatação a que podemos chegar, à luz das evidências disponíveis, é a de que houve escassos e esporádicos vínculos entre duas questões que, em princípio, deveriam estar estreitamente relacionadas: carga tributária e qualidade dos serviços públicos. De fato, é bastante plausível supor viável a emergência de um pacote simbólico estruturado em torno da questão afeta ao "bom uso do dinheiro público", mas tal jamais ocorreu. Prevaleceu, então, uma forma claramente determinada de se estruturar o pacote simbólico da "infraestrutura sucateada": aquela que apontava para a privatização imediata dos serviços tidos como deficientes. A divulgação de um tal pacote contou, como vimos, tanto com o patrocínio de poderosas entidades representativas do empresariado quanto do próprio poder público federal.

Uma vez que não dispomos de séries estatísticas sobre o tema, só nos resta especular sobre a ressonância que tal pacote angariou entre a opinião pública brasileira como um todo. Porém, dado que a insatisfação dos cidadãos com a qualidade dos serviços públicos na primeira metade da década de 1990 era enorme, temos razões para crer que tal pacote deva ter tido ampla ressonância social.

\section{A "INCOMPETÊNCIA EMPRESARIAL"}

Como já foi dito, dentre a variedade de itens capazes de prover a estruturação de determinado pacote simbólico, em grande parte providos pela formulação original da CNI, não se encontra o tema da "incompetência empresarial". Contudo, pudemos perceber ao longo da pesquisa a existência de alguns grupos e agentes que não concordavam com essa exclusão; notamos a emergência de um pacote simbólico estruturado essencialmente em torno do "atraso" e da "desatualização", tanto do nosso parque industrial como um todo, quanto dos métodos e técnicas gerenciais e administrativas empregados pela nossa classe empresarial.

Inclusive entre expressivas lideranças empresariais persistia a visão da empresa nacional como uma entidade ainda bastante atrasada no que dizia respeito aos seus métodos produtivos e gerenciais. Por exemplo, segundo o vicePresidente do Sindicato da Indústria da Construção Civil de São Paulo, Eduardo Zaidan, a execução de obras civis no Brasil, em geral, leva o dobro do tempo que em qualquer país desenvolvido, devido à falta de escala de produção, o que obriga os construtores a produzir os componentes utilizados na edificação no próprio canteiro de obras. Segundo ele, o escasso desenvolvimento da indústria de componentes já acabados para a construção civil no Brasil leva as construtoras a recorrer a métodos artesanais, o que, por sua vez, impõe ritmo lento ao andamento das obras (OBRAS CIVIS DEMORAM, 1997, p. 5). Porém, esse tipo de crítica é bastante rara entre os agentes que participam do debate afeto ao Custo Brasil, prevalecendo, pois, a idéia de que a empresa nacional em todos os seus setores - pelo simples 
fato de sobreviver à crise - já teria alcançado um patamar ótimo/máximo de eficiência, já tendo feito, conseqüentemente, tudo o que estava a seu alcance.

No debate sobre o Custo Brasil, no que respeita ao seu impacto sobre o preço do transporte no país, não apenas a má conservação das estradas e os entraves burocráticos foram criticados: os próprios empresários foram criticados pela sua lentidão em aperfeiçoar a gestão de seus negócios. O Professor de Engenharia de Transportes, Paulo Fernando Fleury, da Coordenação de Programas de Pós-Graduação em Engenharia (COPPE), da UFRJ, afirmava que grande parte do desperdício era culpa dos próprios empresários. "Para carregar um caminhão, as empresas nacionais levam entre seis e oito horas, enquanto em países como os Estados Unidos isso é feito em meia hora" (TRANSPORTE POR RODOVIA, 1997, p. 17).

Dessa forma, podemos afirmar que o pacote da "incompetência empresarial", apesar de culturalmente viável, não contou com um patrocinador constante e eficiente, o que se constitui em um pré-requisito para a sua divulgação e disseminação entre estratos sociais mais amplos de nossa sociedade. Que apenas algumas poucas lideranças empresariais e acadêmicas tenham feito uso de um pacote com essa estruturação não chega a ser um fato surpreendente. Veja-se, por exemplo, o caso do documento original da CNI sobre o tema do Custo Brasil que isentava, de saída, os empresários e seus métodos pela baixa competitividade da economia brasileira. Porém, não deixa de ser surpreendente que outros setores sociais, por exemplo as entidades representativas da classe operária, não tenham se interessado em patrocinar tal pacote.

\section{A "PRECARIEDADE DOS SERVIÇOS DE SAÚDE E EDUCAÇÃO"}

O não-uso do pacote afeto à "incompetência empresarial" por parte das esquerdas no debate dedicado ao Custo Brasil é, como afirmo, no mínimo surpreendente. $\mathrm{O}$ mais intrigante porém, de um ponto de vista mais geral, é a limitação sistemática das esquerdas a um padrão de estruturação de seus pacotes simbólicos em torno de elementos de ordem estritamente econômica. A decorrência óbvia disso é que as esquerdas estruturam seu pacotes simbólicos destinados ao debate sobre as causas do Custo Brasil de maneira em tudo semelhante àquela efetuada por seus adversários.
O valor do exame desse pacote reside então, entre outras coisas, no fato de nos permitir perceber as limitações dos pacotes simbólicos veiculados pela esquerda brasileira.

Como vimos, o termo ganha repercussão e apelo de abrangência nacionais a partir da sua veiculação nos documentos da CNI, que listava como componentes do conceito elementos como a carga tributária, a legislação trabalhista e seus encargos, a infra-estrutura de transportes, telecomunicações e energia, as taxas de juros, a regulamentação da atividade econômica e a precariedade dos sistemas de educação e de saúde. Conseqüentemente, no mínimo a partir da divulgação do documento da CNI, todos os elementos nele contidos tornaram-se culturalmente disponíveis para os agentes e instituições envolvidos no debate, podendo então assistir-se a um número quase ilimitado de formas possíveis de se estruturar os pacotes simbólicos voltados para o debate sobre o "custo Brasil" a partir desses componentes.

Até onde pudemos, nenhum dos representantes do Estado ou do setor privado envolvidos no debate preocupou-se em desenvolver, sequer minimamente, um pacote simbólico estruturado em torno da precariedade dos serviços de saúde e de educação. Esta omissão é, claro, perfeitamente compreensível, pelo menos do ponto de vista dos empresários. Afinal de contas, suscitar uma reflexão sobre o estado dos serviços de educação e de saúde poderia significar arriscar-se apenas e tão-somente a gerar um novo aumento da carga tributária, sem a correspondente melhoria - pelo menos a curto prazo - dos ditos serviços. Assim, estar-se-ia arriscando trocar por um aumento direto e imediato no Custo Brasil uma redução indireta e a se realizar em prazo indeterminado. Não fôra, afinal de contas, sob o pretexto de incrementar o atendimento dos serviços de saúde pública que o governo federal criou mais um imposto - a famosa CPMF, também popularmente conhecida como o "imposto do cheque"?

Do ponto de vista do governo federal, também não seria interessante estruturar um pacote simbólico em torno desse aspecto da questão. Afinal de contas, isso implicaria colocar sob crítica, no mínimo, a própria existência da CPMF e, no limite, a eficiência e a probidade da sua gestão dos recursos públicos alocados nas áreas de educação e de saúde.

Finalmente, restariam as esquerdas como 
agentes passíveis de (re)colocar a educação e a saúde públicas como componentes importantes, senão centrais, da armação estruturante de um pacote simbólico destinado a participar do debate sobre as causas do Custo Brasil. Afinal, na medida em que compunham essa faixa do espectro político importantes entidades representativas dos trabalhadores e dos consumidores, seria perfeitamente natural tal inclusão. Assim procedendo, as esquerdas poderiam pelo menos em parte redirecionar os rumos do debate, bem como ampliar o público que dele participava - que, convém lembrar, até então restringia-se às elites econômicas e políticas do país. Lançando mão de temas de amplo interesse popular, como sempre o são o acesso aos serviços de educação e saúde públicas, as esquerdas possivelmente se permitiriam inverter as prioridades da pauta de discussões - no caso, do econômico para o social - e, no limite, encaminhá-lo de maneira a alterar uma correlação forças no campo da disputa sobre a modelagem da cultura dos assuntos públicos brasileiros que até então lhe era essencialmente desfavorável.

Isso se torna ainda mais provável se levarmos em conta que a cultura política vigente nos países de Primeiro Mundo - que alguns preferem designar como "nova cultura política" - tem como característica distintiva a separação das agendas relativas à política social e à política tributária, o que seria impensável até os anos 1970 (CLARK \& INGLEHEART, 1998).

Contudo, até onde as evidências permitem observar, tal jamais aconteceu. Tome-se como exemplo o famoso simpósio dedicado ao exame do Custo Brasil organizado pelo Partido do Trabalhadores (PT) em 1996, e que contou com a presença de representantes da CUT. Os debates foram organizados em torno de temas como "política econômica e custo Brasil", "custo tributário", "custo do transporte e da infraestrutura" e "custo do trabalho". Prevaleceu, como se pode observar, o encaminhamento usualmente dado ao problema: ênfase nas questões econômicas e legais. As questões afetas a educação e a saúde públicas não foram objeto de uma discussão específica, merecendo, quando muito, menções indiretas e esporádicas dos palestrantes.

Conseqüentemente não se nota, nesse esforço particular de importantes segmentos da esquerda brasileira em discutir o Custo Brasil, nenhuma tentativa de se estruturar um pacote simbólico a partir de uma perspectiva que fosse mais próxima dos interesses imediatos dos setores populares, ou sequer de um ângulo que lhe permitisse alterar uma correlação de forças no confronto de símbolos e representações culturais que lhe era tão desfavorável. Mesmo nos debates dedicados aos custos do trabalho, nota-se os representantes da esquerda numa posição essencialmente ambígua, quando não francamente defensiva, frente aos críticos da legislação e dos encargos trabalhistas, os quais eram tidos - como sempre - como os principais responsáveis por parcela importante do Custo Brasil. Em suma, trata-se de um simpósio que poderia com tranqüilidade ter sido organizado por representantes do Palácio do Planalto ou da FIESP.

Como procurei demonstrar, é entre os setores identificados com a esquerda brasileira que podemos encontrar os grandes prejudicados pela emergência e disseminação do pacote simbólico conhecido como o dos "elevados encargos trabalhistas". Face às críticas que atingiam a legislação trabalhista, as esquerdas de maneira geral evitaram envolver-se no debate sobre as causas do Custo Brasil. E, quando o fizeram, permaneceram reféns da mesma lógica prevalecente na maneira pela qual a elite política e empresarial armava internamente seus pacotes simbólicos. Tal constatação torna-se evidente ao percebermos, por exemplo, que ela insistia em enfatizar os aspectos econômicos e legais do debate. $E$ as esquerdas, mesmo no que diz respeito às questões econômicas, renunciaram sistematicamente a ampliar a discussão, de modo a nele incluir, por exemplo, a mensuração dos supostos índices de eficiência e produtividade das empresas. De fato, as únicas vozes a criticarem a suposta eficiência empresarial da indústria brasileira foram alguns membros da universidade brasileira e os próprios empresários (poucos, claro). Partiam as esquerdas, pois, do mesmo pressuposto que norteava a armação deste pacote simbólico na versão das elites economicamente dominantes: as causas do custo Brasil devem ser buscadas sempre no Palácio do Planalto e na legislação trabalhista, nunca entre os empresários ou em quaisquer outros endereços. A recusa em apostar na estruturação de um pacote simbólico voltado para a "precariedade dos serviços de saúde e educação" é uma evidência a mais a confirmar esse padrão.

VII. A “NECESSIDADE DE MUDANÇAS 


\section{INSTITUCIONAIS".}

O tema dos "elevados custos administrativos" que oneram a produção nacional e lhe diminuíam a competitividade também constava do documento original da CNI sobre as causas do Custo Brasil. Nesta pesquisa pudemos encontrar personagens e instituições que estruturaram pacotes simbólicos em torno desse tema, mas ampliando-o consideravelmente. De fato, constata-se a existência de determinadas vozes que, indo além do tema já há muito tempo conhecido da "desburocratização", defendiam nada menos do que a necessidade de "mudanças institucionais" para dar conta de algumas das causas, que entendiam serem centrais, do Custo Brasil. Assim, à medida em que se constituiu uma nova ordem discursiva, com uma determinada abordagem da história e das origens do Custo Brasil, para não mencionar a apresentação de "soluções" para esse problema, faz sentido falar de um pacote simbólico estruturado em torno do tema da necessidade de "mudanças institucionais".

Para tanto é indispensável fazer referência a alguns líderes empresariais como Roberto Nicolau Jeha, Diretor-Presidente da Indústria de Papel e Papelão São Roberto S/A, que defendia a necessidade de mudanças institucionais, as quais afetariam a forma e o conteúdo dos processos pelos quais se estruturava a definição das políticas industriais. Ele afirmou ser "inadiável acabarmos com as causas do Custo Brasil. Urge também criarmos uma estrutura institucional de governo que fortaleça o espaço de atuação do Ministério da Indústria e Comércio, o qual deveria ser o efetivo coordenador dessa política, por meio de um Conselho de Política Industrial e Comércio Exterior com a participação não só de outros ministérios, mas também de representantes do setor privado, com a tarefa de estabelecer nesse campo políticas globais, setoriais, regionais, de defesa de concorrência, anti-dumping e outras necessárias de uma maneira mais competente e articulada do que hoje" (A INDÚSTRIA E O REAL, 1995, p. 22).

Já Luiz Fernando Furlan, Presidente do Conselho de Administração do grupo Sadia e Diretor do Departamento de Comércio Exterior da FIESP criticou o excesso de burocracia que limitava a competitividade do exportador brasileiro, identificando-o como uma das causas do Custo Brasil: o "grande obstáculo para incre- mento das exportações brasileiras são as barreiras criadas no próprio país, por intermédio do chamado Custo Brasil, um misto do excesso de burocracia e de impostos com a escassez de infraestrutura e eficiência, que faz os produtos nacionais perderem competitividade. Sistematicamente denunciados pelas classes produtoras, os males do Custo Brasil são amplamente conhecidos pelas autoridades, que, diante de platéias, costumam fazer coro aos reclamos dos empresários. Na hora de tomar medidas concretas, porém, tanto o Executivo quanto o Legislativo acabam decepcionando" (ABAIXO TODAS AS BARREIRAS, 1996, p. 21).

Outras mudanças institucionais, também relativas à desburocratização, foram defendidas, remetendo-se ao debate do Custo Brasil. E, quando lançavam mão das análises de custos, tais argumentos ganhavam em ressonância. Um dos que se bateram nesse sentido foi o Presidente do Sindicato da Micro e Pequenas Indústrias do Estado de São Paulo (SIMPI), Joseph Couri. Segundo ele, em algumas empresas, $13 \%$ dos funcionários tinham a única função de tratar de procedimentos burocráticos que se faziam necessários segundo a legislação legada pelo governo federal, Estados e Prefeituras. Da mesma forma, em função do impacto no preço final dos produtos, a burocracia provoca desemprego e falências de muitas empresas, já que os custos elevados são incompatíveis com a globalização da economia (PESQUISA INDICA, 1997, p. 16).

Também se lançou mão de comparações entre a estrutura legal e burocrática da gestão das exportações para, sob a ótica da "necessidade de mudanças institucionais", pleitearem-se mudanças nas regras de exportação. Não era incomum que tais argumentos se fizessem acompanhar de elementos típicos da retórica da "elevada carga tributária": "Essa "exportação de tributos e encargos' retira perto de $13 \%$ da capacidade de competição do made in Brazil no mercado mundial. Exemplo: a colocação de um par de sapatos de Franca, SP, ou de Novo Hamburgo, RS, no mercado de Nova York, continua amarrada por 1214 atos legais, exigindo do exportador 57 procedimentos burocráticos. Essa regulamentite [sic] estrepitosa envolve a autoridade de 72 órgãos e repartições federais, estaduais e municipais" (FIM DA CARGA BURRA?, 1996, p. 11).

Finalmente, não faltaram grupos e agentes que, 
defendendo a necessidade de mudanças amplas no padrão das instituições dedicadas ao fomento econômico, acabavam por pleitear reformas institucionais que beneficiassem seus setores de atuação.

À medida em que ia piorando o desempenho da balança comercial sob o Plano Real, mais e mais os exportadores iam descobrindo as vantagens de esgrimir os argumentos afetos ao pacote da "necessidade de mudanças institucionais" em se tratando de fazer valer suas reivindicações. O argumento pode ser sintetizado a partir de uma frase de Senador Fernando Bezerra (PMDB-RN), Presidente da Confederação Nacional da Indústria (CNI): "O déficit da balança comercial não é resultante de excesso nas importações, mas de problemas nas exportações. Não é o caso de frear as importações. Isso significaria um freio na economia. O que precisamos é de estímulo às exportações, o que passa por uma política firme de reduzir o Custo Brasil" (CNI QUER REDUZIR ENCARGO, 1996, p. 31).

Por exemplo, ainda em 1996 o governo manifestou sua pretensão de ampliar os financiamentos concedidos aos exportadores pelo Finamex, do Banco Nacional de Desenvolvimento Econômico e Social (BNDES) e de criar o seguro de crédito à exportação, precisamente como resposta às críticas empresariais à sua morosidade em reduzir o Custo Brasil (KANDIR ESTUDA REDUÇÃO, 1996, p. 4).

Em conclusão, à luz das evidências apontadas, podemos perceber que tanto os defensores da desburocratização pura e simples, quanto aqueles que buscavam mudanças no padrão de atuação das instituições regulamentadoras ou dedicadas ao fomento econômico com vistas a favorecer seus próprios interesses, puderam estruturar um determinado pacote simbólico voltado para os debates relativos ao Custo Brasil, que teve grande ressonância e eficácia. Tiveram ao seu favor, nessa empreitada, a concepção amplamente disseminada de que a administração pública é excessivamente burocratizada e que tal "burocratização" influencia negativamente a produtividade e a competitividade da economia nacional.

VIII. O “CÂMBIO SOBREVALORIZADO”, A “ALTA TAXA DE JUROS” E OUTROS COMPONENTES DO PLANO REAL À LUZ DO DEBATE SOBRE AS CAUSAS

\section{DO “CUSTO BRASIL"}

Tendo se convertido em principal alvo das críticas do empresariado, o Palácio do Planalto pronunciou-se repetidas vezes sobre o tema do Custo Brasil. De maneira geral, o Planalto acatou as teses do documento da CNI e, via de regra, adotou uma postura defensiva frente às diversas críticas inspiradas, em maior ou menor grau, pela Cartilha custo Brasil.

Em determinado momento, face ao desequilíbrio da balança comercial, a própria cotação da moeda nacional frente ao dólar passou a ser incluída como um componente importante do Custo Brasil. O tema recorrente das críticas era a sobrevalorização do Real frente ao dólar, bem como a elevada taxa de juros, principais âncoras da estabilização monetária, mas que eram alvos de ataques recorrentes do empresariado, tidos como responsáveis pelo encarecimento dos produtos brasileiros no mercado externo. Dentre vários outros, manifestaram-se nesse sentido José Augusto de Castro, Diretor-Técnico da AEB (Associação de Comércio Exterior do Brasil) e José Bueno, Diretor-Técnico do Instituto Brasileiro de Executivos de Finanças (IBEF-SP): "Se nossos concorrentes [externos] oferecem prazos e financiamentos a taxas de $4 \%$ ao ano, ou temos e criamos condições para oferecer o mesmo ou estamos fora do mercado" (CUSTO BRASIL E COMPETITIVIDADE, 1996, p. 3).

Também o Presidente de um dos mais importantes grupos empresariais do país, Antonio Ermírio de Morais, pronunciou-se de maneira crítica contra a manutenção de elevadas taxas de juros, tidas como responsáveis pelo encarecimento do Custo Brasil (CUSTO BRASIL PODE FRUSTRAR, 1998, p. 7).

Em 1996 o Presidente Fernando Henrique Cardoso assim se manifestava a esse respeito: "Existem duas maneiras de melhorar a competitividade externa: uma maneira errada e fácil; e outra certa e mais complexa. A primeira é simplesmente mexer no câmbio. Isso apenas transfere renda para os exportadores [...]. A outra maneira de enfrentar o problema, a correta, é os exportadores melhorarem a produtividade, o que já estão fazendo, e o governo reduzir o custo Brasil, o que também já está sendo feito" (O QUE PASSA NA CABEÇA, 1996, p. 18-22).

Embora diferentes setores e agentes tenham se 
pronunciado quanto à inadequação das taxas de câmbio e juros praticadas pelo país a partir do Plano Real, não pudemos perceber ao longo da pesquisa nenhum pacote simbólico estruturado principal ou exclusivamente em torno desses temas. É que, por um lado, parecia haver uma crença generalizada - amplamente fomentada dentre outros por importantes autoridades como Gustavo Franco, Presidente do Banco Central de que tais taxas eram fundamentais para a manutenção do plano de estabilização. Sem elas, argumentava-se, poder-se-ia permitir a volta da inflação e a fuga de capitais. A disseminação de tal crença parece ter jogado um papel decisivo na inviabilização de pacotes que fossem estruturados em torno da crítica à taxa de juros e câmbio. Seria necessário o choque da maxidesvalorização de janeiro de 1999 para pôr por terra tais mitos.

Por outro lado, as tensões impostas sobre a economia pelo desequilíbrio da balança comercial foram atenuadas tanto pelo ingresso de capitais estrangeiros - atraídos precisamente pelas taxas de juros - quanto pela concessão de compensações aos exportadores prejudicados pelo câmbio sobrevalorizado, das quais a Lei Kandir certamente é a mais importante.

Dessa forma, parece claro que determinados aspectos da política econômica tenham sido eventualmente listados como componentes importantes do Custo Brasil e, por decorrência, tenham se tornado culturalmente disponíveis para a luta simbólica em torno desse tema. Contudo, a despeito disso, não se nota por parte dos agentes e instituições aqui examinados nenhum esforço consistente para estruturar um pacote simbólico em torno desses itens no que respeita ao debate sobre as causas e as eventuais soluções para o Custo Brasil. Dado o conjunto de crenças relativas ao papel desempenhado pela taxa de juros e de câmbio na estabilidade da moeda nacional, um tal pacote parece se constituir em uma impossibilidade cultural.

\section{CONCLUSÃO}

Como mencionado, foi de modo extremamente amplo e detalhado que a CNI definiu os componentes prováveis do Custo Brasil. Contudo, não encontramos nenhum agente ou instituição disposto a estruturar um pacote simbólico com base em todas as componentes da formulação desse problema. Aliás, nem a própria CNI. Afinal de contas, essa entidade tem centrado sua atuação desde a publicação daquele documento quase que exclusivamente em torno dos pacotes afetos aos "elevados custos trabalhistas", à "alta carga tributária" e à "infraestrutura deficiente", merecendo menor atenção as questões do "câmbio sobrevalorizado" e da "alta taxa de juros". Também se dedicou algum esforço ao que se refere à "necessidade de mudanças institucionais". Nem a "incompetência empresarial" e nem a "precariedade dos serviços de saúde e de educação" constituíram-se em temas sequer minimamente a serem desenvolvidos pela CNI e, surpreendentemente, nem pelas próprias esquerdas.

Tanto as questões afetas à educação e à saúde, para não mencionar outros temas relacionados em algum grau à qualidade de vida ${ }^{1}$, permaneceram estranhamente ausentes da armação dos pacotes simbólicos das esquerdas. Agindo assim, as esquerdas perderam a oportunidade de não só atrair ao debate outros segmentos da sociedade que poderiam vir em seu apoio na luta política, como também colocaram-se repetidamente em uma posição de inferioridade, de caráter defensivo e apenas reativo. Podemos constatar então que, ou as esquerdas não souberam armar de modo que lhe fosse favorável tal pacote simbólico ou, se o fizeram, não conseguiram para a sua versão a divulgação na grande imprensa e o impacto sobre a cultura política brasileira que seus adversários lograram.

Naturalmente, tais hipóteses não são excludentes. A hipotética falta de habilidade das esquerdas em forjar a armação de um pacote simbólico que lhe fosse mais favorável pode perfeitamente ter coexistido com a flagrante desproporção de meios e apoios físicos para divulgá-lo na sociedade brasileira, como convém ao patrocinador de qualquer pacote.

Cabe aqui pelo menos uma menção às características estruturais da imprensa que se organiza enquanto propriedade privada numa sociedade capitalista. À medida em que as empresas privadas são os principais anunciantes

\footnotetext{
1 Na retórica do cidadão comum o Custo Brasil foi identificado até mesmo nos engarrafamentos do trânsito, responsáveis por considerável perda de tempo, dinheiro e por males a saúde. A esse respeito ver-se SAUDADE DO RODÍZIO (1997, p. 122). Outro uso possível do termo refere-se à questão ambiental: "Crime ambiental, o outro Custo Brasil” (CRIME AMBIENTAL, 1998, p. 2).
} 
nos meios de comunicação de massa, torna-se fácil para elas pressionarem os órgãos da imprensa escrita e falada para divulgarem suas demandas e projetos junto à sociedade. Nesse caso, sequer é necessária a ameaça de rompimento dos contratos de publicidade. Sendo do interesse dos proprietários dos órgãos de imprensa manterem-se em boas relações com seus anunciantes, e sendo eles próprios empresários, pode-se imaginar que estes dificilmente oporão resistência à divulgação daquilo que interessa ao empresariado ou que abrirão espaço para a divulgação de teses contrárias ao espírito do capitalismo e da livre iniciativa (OLIVEIRA, 1991).

Dada tal correlação de forças e, assumindo-se aqui também a hipótese da inabilidade das esquerdas na armação de um possível pacote simbólico estruturado em torno do tema da "precariedade dos serviço de saúde e de educação", conclui-se que não se tem neste caso nenhuma particularidade notável. Desde o início da década de 1990 e, particularmente a partir do início do processo de reforma constitucional, as esquerdas brasileiras vêm se notabilizando muito mais pela sua atitude obstrucionista e de inviabilização do debate que por um esforço criativo e original no sentido de redirecioná-lo no interesse da modernização econômica, do avanço da justiça social e da consolidação da democracia no país (ARAGÃO, 1996).

É de se concluir, portanto, que a forma pela qual se vem discutindo o Custo Brasil é uma manifestação a mais da hegemonia dos grupos empresariais e das elites políticas dominantes no processo de conformação da cultura política do Brasil contemporâneo.

Uma segunda conclusão importante diz respeito ao nexo entre a cultura deste assunto público, o Custo Brasil, e algumas das características da cultura política prevalecente no Brasil contemporâneo, que aparece sendo recorrentemente descrita como dominada pela retórica e pelos elementos constituintes do neoliberalismo.

As propostas sociais e econômicas, inspiradas pelo neoliberalismo, têm entrado na disputa pela definição dos rumos e ênfases que se deseja imprimir às reformas econômicas em diversos países da América Latina como contedores de importância significativa. Seguindo a alegada lógica "inevitável” imposta pelo processo de globalização econômica, o ideário neoliberal propõem introduzir um novo tipo de relacionamento entre Estado e a sociedade civil, que enfatiza uma concepção minimalista tanto do Estado quanto da democracia. Os cidadãos, nessa concepção, deveriam cuidar de si e de seu bemestar privadamente e a partir de seus próprios meios, e a cidadania passaria a ser entendida cada vez mais como a integração individual no mercado (ALVAREZ, DAGNINO \& ESCOBAR, 1998).

Uma vez que partilho do pressuposto de que o ideário neoliberal parece desempenhar um papel hegemônico no interior das culturas políticas latino-americanas contemporâneas, torna-se necessário indicar a qual concepção desse conceito me refiro.

O conceito de cultura política tem permanecido largamente restrito àquelas atitudes e crenças sobre a arena política, entendida esta tanto em termos partidários quanto institucionais. Nessa concepção original de cultura política, ela é usada para designar as orientações especificamente políticas, as atitudes com respeito ao sistema político, as relações entre suas diversas partes e o papel dos cidadãos na vida pública (MOISÉS, 1995, p. 86). Em elaborações posteriores, seus autores sofisticaram o conceito ao referir-se à cultura política como consistindo no sistema de crenças empíricas, símbolos expressivos e valores que definem a situação na qual a ação política tem lugar (CHILCOTE, 1997, p. 235). Dessa forma, a cultura política relaciona-se, entre outras coisas, às crenças mantidas pelos indivíduos em relação à política, à forma como ela opera, ao papel dos indivíduos no sistema e aos padrões de relacionamento do Estado com a sociedade.

Nesse sentido, tornou-se plausível supor a existência de um nexo evidente entre a cultura política dos cidadãos e o tipo de regime político prevalecente. De fato, um volume considerável de pesquisas foi desenvolvido ao longo das décadas de 1940 e 1950 buscando demonstrar que as características de determinado sistema político poderiam ser derivadas da forma pela qual os seu cidadãos encaravam e se comportavam diante de suas instituições públicas e as formas assumidas pelo exercício suas atividades políticas. Nesse sentido, a cultura política seria a determinante principal da forma e do conteúdo assumidos por um certo sistema político.

O que se constata é uma identidade entre a formulação do que vem a ser a cultura política e o 
que é entendido tradicionalmente como o campo da política. Assim, pressupõe-se que haja uma congruência entre aquilo que a cultura historicamente dominante veio a definir como sendo propriamente $a$ política e aquelas crenças que escoram ou minam as regras estabelecidas de um determinado "jogo político".

O problema é que tais concepções de cultura política tomam o político como dado e falham em atacar um aspecto chave das lutas simbólicas exploradas aqui. Como determinados autores notam, muito freqüentemente a política é referida de uma forma que já presume um sentido consensual e fundacional. Concordamos com afirmações de alguns autores (ALVAREZ, DAGNINO \& ESCOBAR, 1998) para quem a análise das questões políticas necessariamente apresenta a questão de por quê uma dada questão é política. Assim, torna- se plausível presumir que é a cultura política que condiciona e expressa esta determinação. Dessa forma, se faz sentido assumir, como aliás vêm fazendo diversos autores - em que pese toda a precariedade inerente a essa afirmação -, que a cultura política dominante na América Latina em geral e no Brasil em particular é dominada pela concepção "minimalista" de Estado e de democracia a que nos referimos, teremos razões para afirmar que o próprio rumo impresso às discussões sobre o Custo Brasil, tanto pelos setores política e economicamente dominantes, quanto pelas próprias esquerdas, pode ser entendido como uma das manifestações da prevalência cultural das teses defendidas pelos grupos identificados com o neoliberalismo sobre essa mesma cultura política.

Recebido para publicação em 10 de setembro de 1998.

Dennison de Oliveira (kursk@cwb.matrix.com.br/dennison@humanas.ufpr.br) é Professor Adjunto do Departamento de História da Universidade Federal do Paraná (UFPR) e Doutor em Ciências Sociais pela Universidade Estadual de Campinas (UNICAMP).

\section{REFERÊNCIAS BIBLIOGRÁFICAS}

ALEXANDER, J. C. \& SMITH, P. 1993. The discourse of American civil society : a new proposal for cultural studies. Theory \& society, n. 22, p. 151-207.

ALMEIDA, M. H. T. \& MOYA, M. 1997. A reforma negociada : o Congresso e a política de privatização. Revista Brasileira de Ciências Sociais, São Paulo, v. 12, n. 34, p. 119-132, jun.

ALVAREZ, S. E., DAGNINO, E. \& ESCOBAR, A. (orgs.). 1998. Culture of politics. Politics of cultures : revisioning Latin American social movements. Boulder : Westwiew Press.

AMARAL FILHO, J. \& LIMA, E. C. P. 1998. Privatização e ajuste fiscal no Brasil. Ensaios FEE, Porto Alegre, v. 19, n. 2, p. 62-91.

ARAGÃo, M. 1996. A ação dos grupos de pressão nos processos constitucionais recentes. Revista de Sociologia e Política, Curitiba, n. 6/7, p. 149-168.

ARCHER, M. 1988. Culture and agency.
Cambridge : Cambridge University Press.

BATTANI, M., HALL, D. R. \& POWERS, R. 1997. Culture's structures : making meaning in the public sphere. Theory \& society, n. 26, p. 781-812.

BENEVIDES, M. V. M. 1994. Cidadania e democracia. Lua Nova, São Paulo, n. 33, p. 557.

BERGER, S. \& DORE, R. (orgs.). 1996. National diversity and global capitalism. Ithaca : Cornell University Press.

BOGGS, C. 1997. The great retreat : decline of the public sphere in the late twentieth-century America. Theory \& Society, n. 26, 741-780.

BRESSER PEREIRA, L. C. 1998. Economia brasileira : uma introdução crítica. São Paulo : 34 .

CARDOSO, C. F. \& VAINFAS, R. (orgs.). 1997. Domínios da história. Rio de Janeiro : Campus.

CHILCOTE, R. H. 1997. Teorias de política comparativa : a busca de um paradigma 
reconsiderado. Petrópolis : Vozes.

CLARK, T. \& INGLEHART, R. 1988. The new political culture : changing dynamics of support for the welfare state and other policies in post industrial societies. In : CLARK, T. N. \& HOFFMAN-MARTINNOT, V. (orgs.). The new political culture. Boulder : Westwiew Press.

CLARK, T. N. \& HOFFMAN-MARTINNOT, V. (orgs.). 1998. The new political culture. Boulder : Westwiew Press.

CNI. 1995. Cartilha custo Brasil. São Paulo : Confederação Nacional da Indústria.

COSTA, J. F. 1995. A ética e o espelho da cultura. Rio de Janeiro : Rocco.

DAVIS, M. 1981. The new right's road to power. New Left Review, p. 28-49, Jul.-Aug.

DIEESE. 1997. O polêmico peso dos encargos sociais no Brasil. DIEESE, n. 12 - Encargos sociais no Brasil. Conceito, magnitude e reflexos no emprego. São Paulo : Departamento Intersindical de Estatística e Estudos SócioEconômicos.

DINIZ, E. 1995. Governabilidade, democracia e reforma do Estado : os desafios da construção de uma nova ordem no Brasil dos anos 90. Dados, Rio de Janeiro, vol. 38, n. 3, p. 385-415.

1997. Crise, reforma do Estado e governabilidade : Brasil 1985-1995. Rio de Janeiro : Fundação Getúlio Vargas.

DREYFUSS, R. A. 1989. O jogo da Direita. Petrópolis : Vozes.

EMIRBAYER, M. \& GOODWIN, J. 1994. Network analysis, culture and the problem of agency. American Journal of Sociology, v. 99, n. 6, p. 1411-1454, May.

EVANS, P. 1995. Embeddeb autonomy : States and industrial transformation. Princeton, New Jersey : Princeton University Press.

FADUL, E. M. C. 1999. Reforma do Estado e serviços públicos : transformação de um modelo ou adaptação a uma nova ordem social? Revista de Administração, São Paulo, 1999 , v. 34 , n. 1, p. 70-78, jan.-mar.

FAVELL, A. A. 1998. Politics that is shared, bounded and rooted? Rediscovering civic poli- tical culture in Western Europe. Theory \& Society, n. 27, p. 209-236.

FERGUSON, T. 1995. Golden rule: the investment theory of party competition and the logic of money-driven political systems. Chicago : University of Chicago Press.

FONES-WOLF, E. A. 1994. Selling free enterprise : the business assault on labor and liberalism. Chicago : University of Illinois Press.

GAETANI, F. 1998. A reforma do Estado no contexto latino-americano : comentários sobre alguns impasses e possíveis desdobramentos. Revista do Serviço Público, Brasília, vol. 49, n. 2, p. 85-104, abr.-jun.

GALBRAITH, J. K. 1989. O pensamento econômico em perspectiva : uma história crítica. São Paulo : Pioneira/Edusp.

GANSON, W. \& MODIGLIANI, A. 1974. Conceptions of social life : a text reader for social phychology. Boston : Little Brown and Company.

1987. The changing culture of affirmative action. Research in Political Sociology, n. 3, p. 137-177.

1989. Media discourse and the public opinion on nuclear power : a constructionist approach. American Journal of Sociology, n. 1, p. 1-37, July.

GENDZEL, G. 1997. Political culture : genealogy of a concept. Journal of Interdisciplinary History, v. XXVIII, n. 2, p. 227-250, Autumm.

GIRARDET, R. 1987. Mitos e mitologias políticas. São Paulo : Companhia das Letras.

GOLD, M. \& DOUVAN, E. 1997. A new outline of social psychology. Washington : American Pychological Association.

HARVEY, D. 1992. A condição pós-moderna : uma pesquisa sobre as origens da mudança cultural. São Paulo : Loyola.

HASKELL, T. L. \& TREICHGRAEBER, R. F. (orgs.). 1996. The culture of the market : historical essays. Cambridge : Cambridge University Press.

JACOBS, R. N. 1996. Civil society and crisis : culture, discourse and the Rodney King 
beating. American Journal of Sociology, v. 101, n. 5, p. 1238-1272, Mar.

KARABEL, J. 1996. Towards a theory of intelectuals and politics. Theory \& Society, $\mathrm{n}$. 25 , p. 205-233.

LEVINE, D. H. (org.). 1993. Constructing culture and power in Latin America. Ann Harbor : University of Michigan Press.

LIMA JR., O. B. 1998. As reformas administrativas no Brasil : modelos, sucessos e fracassos. Revista do Serviço Público, Brasília, v. 49, n. 2, p. 5-31, abr.-jun.

LINDBLOM, C. E. 1981. O processo de decisão política. Brasília : Ed. Unb.

LOURENÇO, G. M. 1998a. Programa de estabilidade fiscal : observações preliminares. Análise Conjuntural, Curitiba, v. 20, n. 9/10, p. 9-11, set.-out.

1998b. Estabilidade fiscal e defesas do Paraná. Análise Conjuntural, Curitiba, v. 20, n. 11/12, p. 3-6, nov.-dez.

MARTINS, L. 1990. A autonomia política do governo Collor. In : FARO, C. (org.) Plano Collor : avaliações e perspectivas. Rio de Janeiro : Livros Técnicos e Científicos.

MATOS FILHO, J. C. \& OLIVEIRA, C. W. 1996. O processo de privatização das empresas estatais brasileiras. Brasília : IPEA.

MELLO, M. F. 1994. Privatização e ajuste fiscal no Brasil. Pesquisa e Planejamento Econômico, Rio de Janeiro, v. 24, n. 3, p. 445517, dez.

MOISÉS, J. A. 1995. Os brasileiros e a democracia : bases sócio-políticas da legitimidade democrática. São Paulo : Ática.

MÜLLER, E. N. \& SELIGSON, M. A. 1994. Civic culture and democracy : the question of causal relationship. American Political Science Review, v. 88, n. 3, p. 635-667, Sept.

NUNES, R. C. \& NUNES, S. P. P. 1998. Privatização e ajuste fiscal : a experiência brasileira. Planejamento e Políticas Públicas, Brasília, n. 17, p. 171-211, jun.

OLIVEIRA, D. 1991. Estado e mercado : telecomunicações no Brasil. Curitiba : Prephacio.
PEDRIANA， N. \& STRYKER，R. 1997. Political culture wars 1960s style : equal employment opportunity - affirmative action law and the Philadelphia Plan. American Journal of Sociology, v. 103, n. 3, p. 633-691, Nov.

PINHEIRO, A. C. \& GIAMBIAGI, F. 1997. Lucratividade, dividendos e investimentos das empresas estatais : uma contribuição para o debate sobre a privatização no Brasil. Revista Brasileira de Economia, Rio de Janeiro, v. 51, n. 1, p. 93-131, jan.-mar.

PORTELLA FILHO, P. 1994. O ajustamento na América Latina : crítica ao modelo de Washington. Lua Nova, São Paulo, n. 32, p. 101-143.

PRZEWORSKI, A. 1989. Capitalismo e socialdemocracia. São Paulo : Companhia das Letras.

1996. Reforma do Estado : responsabilidade política e intervenção econômica. Revista Brasileira de Ciências Sociais, São Paulo, v. 11, n. 32, p. 18-40, out.

PRZEWORSKI, A. \& WALLERSTEIN, I. 1988. Structural dependence of the state on capital. American Political Science Review, v. 82, n. 1, p. 12-13, Mar.

RAJCHMAN, J. (org.). 1995. The identity in question. London : Routledge.

RÉMOND, R. (org.). 1996. Por uma história política. Rio de Janeiro : UFRJ/FGV.

RIBEIRO, V. M. R. 1994. A revisão constitucional : reforma ou contra-reforma? Paper apresentado ao Grupo de Trabalho "Elites políticas", no $19^{\circ}$ Encontro Anual da ANPOCS. Caxambu : mimeo.

SAES, D. 1996. Democracia e capitalismo no Brasil : balanços e perspectivas. Revista de Sociologia e Política, Curitiba, n. 6/7, p. 129148.

SANTOS, F. G. M. 1994. Dinâmica congressual e regulação econômica : o caso da lei portuária. Paper apresentado ao Grupo de Trabalho "Elites Políticas", no $19^{\circ}$ Encontro Anual da ANPOCS. Caxambu : mimeo.

SCHWARTSMAN, A. 1999. A crise cambial e o ajuste fiscal. Revista de Economia Política, São Paulo, v. 19, n. 1, p. 5-29, jan.-mar. 
SILVA, L. I. L. (coord.). 1997. Custo Brasil : mitos e realidades. Petrópolis : Vozes.

SOLA, L. 1994. Estado, reforma fiscal e governabilidade democrática : qual Estado? Novos Estudos CEBRAP, São Paulo, n. 38, p. 189-205, mar.

SWIDLER, A. 1986. Culture in action : symbols and strategies. American Sociological Review, n. 51, p. 273-286, Apr.

SZELÉNYI, S., SZELÉNYI, I. \& POSTER, W. R. 1996. Interests and symbols in post communist political culture : the case of Hungary. American Sociological Review, v. 6, n. 3, p. 466-478, Jun.
USEEM, M. 1983. Business and politics in the United States and United Kingdom. Theory \& Society, n. 12, p. 281-308, May.

1984. The inner circle : large corporations and the rise of business political activity in the U. S. and U. K. Oxford : Oxford University Press.

VIANA, A. L. A. 1993. Crise do Estado, neoliberalismo e descentralização : a reforma do sistema de saúde no Brasil. Caxambu : ANPOCS.

WOSHINSKY, O. H. 1995. Culture and politics : an introduction to mass and elite behavior. Prentice Hall : Englewood Cliffs.

\section{OUTRAS FONTES}

A indústria e o Real. Veja, São Paulo, 29.dez.1995, p. 22.

A polêmica dos encargos sociais. Os salários, no Brasil, são apenas $23 \%$ do valor agregado na indústria. O Estado de S. Paulo, São Paulo, 23.fev.1996, p. 7.

Abaixo todas as barreiras. Veja, São Paulo, 29.nov.1996, p. 21.

Bonito, mas maltratado : pesquisa da Embratur obtida com exclusividade por ISTOÉ revela as causas que afugentam turistas e fazem o Brasil perder US\$ 45 bilhões ao ano. Isto $E$, São Paulo, 11.mar.1998, p. 7.

CNI quer reduzir encargo das empresas. Projeto prevê uma queda de despesas com a folha de pagamento em até 30\%. O Estado de S. Paulo, São Paulo, 21.dez.1996, p. 31.

Crime ambiental, o outro custo Brasil. Gazeta Mercantil, São Paulo, 20.jul.1998, p. 2.

Custo Brasil desafia competitividade externa. Para Simonsen, problema são os portos, as rodovias, os encargos trabalhistas e a carga fiscal. $O E s$ tado de S. Paulo, São Paulo, 4.jan.1996, p. 10.

Custo Brasil e competitividade na exportação. $O$ Estado de S. Paulo, São Paulo, 12.ago.1996, p. 3.

Custo Brasil menor, para reduzir o déficit comercial. O Estado de S. Paulo, São Paulo, 13.set.1996, p. 6.
Custo Brasil na prática. O Estado de S. Paulo, São Paulo, 15.out.1997, p. 13.

Custo Brasil pode frustrar exportações, diz Ermírio. Empresário afirma que taxas de juros elevadas dificultam o crescimento das vendas externas. O Estado de S. Paulo, São Paulo, 5.jan.1998, p. 7.

Custo Brasil também encarece produção de trigo. O Estado de S. Paulo, São Paulo, 15.fev.1997, p. 9.

Empresas culpam Custo Brasil. O Estado de $S$. Paulo, São Paulo, 12.ago.1996, p. 31.

Estradas estão praticamente intransitáveis. O Estado de S. Paulo, São Paulo, 18.jun.1997, p. 2.

Ferreira pede pressa no debate sobre Custo Brasil. O Estado de S. Paulo, São Paulo, 16.jan.1997, p. 12.

Fim da carga burra? O Estado de S. Paulo, São Paulo, 5.ago.1996, p. 11.

Kandir estuda redução do Custo Brasil. O Estado de S. Paulo, São Paulo, 13.jun.1996, p. 4.

Malan defende a redução dos encargos trabalhistas. Futuro Ministro diz que acabaram os "bons tempos" para os exportadores. Veja, São Paulo, 28.dez.1994, p. 1-5.

Mãos sem obras. Exame, São Paulo, 29.dez.1995, p. 12.

Nova central fará proposta antidesemprego. CGT 
fortalecida com ingresso do grupo de Alemão que reduzir o Custo Brasil. O Estado de $S$. Paulo, São Paulo, 27.fev.1996, p. 3.

Novo Custo Brasil. O Estado de S. Paulo, São Paulo, 13.jun.1996, p. 11.

O que passa na cabeça dele : entrevista com o Presidente sobre economia, reeleição, Gustavo Franco e Maluf. Exame, São Paulo, n. 625, 18.dez.1996, p. 18-22.

Obras civis demoram o dobro no país. O Estado de S. Paulo, São Paulo, 11.ago.1997, p. 5.

Para CNI, modernização de portos é lenta. Quatro anos depois de adotada, lei de modernização ainda não reduziu custo portuário. $O$ Estado de S. Paulo, São Paulo, 5.jul.1997, p. 5.

Pesquisa indica participação no Custo Brasil. $40 \%$ do total de horas trabalhadas nas empresas são para as questões burocráticas. $O$ Estado de $S$. Paulo, São Paulo, 24.mar.1997, p. 16.

Porto brasileiro é $45 \%$ mais caro. Estudo do BNDES mostra que movimentação portuária em Santos custa mais do que na Europa. $O$ Estado de S. Paulo, São Paulo, 9.jul.1997, p. 8.

Quando o telefone der linha... Hoje, os mais beneficiados pela privatização são o governo e os acionistas. A partir de 1997, serão os usuários. Exame, São Paulo, n. 625, 1996, p. 22-25.

Saudade do rodízio. Exame, São Paulo, n. 636, 21.maio.1997, p. 122.

Transporte por rodovia dá prejuízo de US\$ 3 bilhões. Estudo do Banco Mundial estima que esse é o valor perdido por ano pela má utilização de ferrovias. O Estado de S. Paulo, São Paulo, 3.ago.1997, p. 17. 